\title{
Structural Modifications and Programmed Cell Death of Chili Pepper Fruit Related to Resistance Responses to Colletotrichum gloeosporioides Infection
}

\author{
Kwang-Hyung Kim, Jae-Bok Yoon, Hyo-Guen Park, Eun Woo Park, and Young Ho Kim
}

\begin{abstract}
First and fifth authors: School of Agricultural Biotechnology and Center for Plant Molecular Genetics and Breeding Research, Seoul National University; second and third authors: Department of Horticultural Science and Center for Plant Molecular Genetics and Breeding Research, Seoul National University; and fourth author: School of Agricultural Biotechnology, Seoul National University, Seoul 151-921, Korea.

Accepted for publication 20 July 2004.
\end{abstract}

\begin{abstract}
Kim, K.-H., Yoon, J.-B., Park, H.-G., Park, E. W., and Kim, Y. H. 2004. Structural modifications and programmed cell death of chili pepper fruit related to resistance responses to Colletotrichum gloeosporioides infection. Phytopathology 94:1295-1304.

Postharvest (detached) and in planta (attached) fruits of pepper plants, Capsicum annuum cv. Jejujaerae (susceptible) and Capsicum baccatum cv. PBC80 (resistant), inoculated with the anthracnose pathogen Colletotrichum gloeosporioides were examined using light, confocal laser scanning, and electron microscopy to compare the cytological differences between the compatible and incompatible interactions. In nonwound inoculation of postharvest pepper fruit, resistant pepper tissues showed a significant increase in the thickness of the cuticle layer compared with that of the

terminal deoxynucleotidyl transferase-mediated dUTP nick end labeling. The oligonucleosomal fragments of DNA were confirmed electrophoretically as DNA laddering. The PCD-positive responses occurred around the inoculation sites early in in planta wound inoculation in the resistant pepper. Nuclear modifications and structural changes of hypersensitivity were also observed in the resistant fruit, including separation of the plasma membrane from the cell wall, dilation of the endoplasmic reticulum, accumulation of electron-dense inclusions in vacuoles, and cytoplasmic vacuolization accompanying fragmentation of the cytoplasm. These structural changes may also implicate PCD-like host responses. In addition, in planta wound inoculation resulted in cell enlargement and cell division during the later stages of infection to form a periderm-like boundary layer around the inoculation site.
\end{abstract} susceptible and noninoculated fruit. Cytological features of programmed cell death (PCD) were observed in the resistant pepper fruit with postharvest inoculation, and these were characterized by positive responses to
Additional keywords: Glomerella cingulata, hypersensitive response.
Anthracnose, which is caused by Colletotrichum species, occurs extensively in chili peppers and has long been a serious problem wherever the plants grow. On pepper, four Colletotrichum species have been reported in Korea: $C$. gloeosporioides, $C$. acutatum, C. coccoides, and C. dematium. Of these, $C$. gloeosporioides and $C$. acutatum comprise more than $90 \%$ of the anthracnose pathogens isolated (36). C. gloeosporioides and C. acutatum attack pepper fruit at all developmental stages, but usually not leaves or stems, which are mostly damaged by $C$. coccoides and C. dematium.

Anthracnose pathogens infect plants by either colonizing subcuticular tissues intramurally or by being established intracellularly (4). The preinfection stages of both are very similar; conidia adhere to and germinate on the plant surface, producing germ tubes that form appressoria, which penetrate the cuticle directly. Following penetration, the pathogens that colonize the intramural region beneath the cuticle invade in a necrotrophic manner and spread rapidly throughout the tissues $(4,31)$. There is no detectable biotrophic stage in this form of parasitism. By contrast, most anthracnose pathogens exhibit a biotrophic infection strategy initially by colonizing between the plasmalemma and cell wall intracellularly. After the biotrophic state, which varies in duration, intracellular hyphae colonize one or two cells and subsequently

Corresponding author: Y. H. Kim; E-mail address: yhokim@snu.ac.kr

Publication no. P-2004-1013-01R

(c) 2004 The American Phytopathological Society develop secondary necrotrophic hyphae $(23,31)$. Therefore, these pathogens are considered hemibiotrophs or facultative biotrophs. C. gloeosporioides infects avocado, chili pepper, and citrus via both types of colonization, producing intracellular biotrophic hyphae in the early stage and forming intramural necrotrophic hyphae at the same time or soon afterward (32).

There are two broad kinds of defense mechanisms in plants. One is the passive or preexisting defense mechanism, which involves structural barriers or strategically positioned reservoirs of antimicrobial compounds that function to prevent tissue colonization $(1,2,13,34)$. In the other mechanism, plants prevent further tissue colonization by de novo reactions following pathogen sensing. This is called active or induced defense and includes biochemical reactions such as hypersensitive necrotic responses, and cytological and histological modifications $(1,16,17)$. Localized cell death (hypersensitive response) prevents biotroph survival and growth, but it does not affect the necrotrophs that utilize dying or dead cells as a food source (45). In leaf and stem (petiole) infections by Colletotrichum species, incompatible reactions occur at an early stage, involving defense structures related to cell-level responses $(14,48,49)$. It is hypothesized that these vegetative tissue resistance responses involve specific gene-forgene interactions. However, the diseases caused by C. gloeosporioides that affect various fruits are not determined by the specific gene-for-gene hypothesis. This pathogen may become more necrotrophic after penetration, and resistance usually involves complex incompatible processes that are governed by multiple genes (39). 
The most serious damage to commercial chili peppers (Capsicum annuum) by C. gloeosporioides occurs in the fruit. Although there have been extensive studies of resistance in Capsicum annuum, these studies have focused mostly on leaf and seedling anthracnose, not on fruit disease. No commercial cultivars resistant to anthracnose have been developed. Consequently, little is known about the resistance of pepper fruit to the anthracnose pathogen. Recently, some varieties showing resistance to pepper fruit anthracnose caused by $C$. gloeosporioides and $C$. acutatum were found in other Capsicum species, such as Capsicum baccatum and Capsicum chinense $(3,5)$. In particular, some lines of Capsicum baccatum show strong resistance to the pathogen, and pathogen inoculation results in no or limited lesions on the pepper fruit (51). Nevertheless, the mechanisms of pepper fruit resistance have not been examined on either a molecular biological or biochemical basis, and no structural defense mechanism has been identified. In this study, we examined the cytological and histological differences between resistant (Capsicum baccatum cv. PBC80) and susceptible (Capsicum annuum cv. Jejujaerae) peppers infected with $C$. gloeosporioides. This histological and ultrastructural study should provide clues to understanding the defense mechanism of pepper fruit against anthracnose pathogens.

\section{MATERIALS AND METHODS}

Pathogen and inoculation. C. gloeosporioides (teleomorph, Glomerella cingulata) isolate 47-3 was obtained from an anthracnose lesion on a Capsicum annuum fruit using single-spore isolation. The fungus was cultured on potato dextrose agar (Difco Laboratories, Detroit, MI) for 7 days in darkness at $25^{\circ} \mathrm{C}$. Ten milliliters of sterile distilled water was added to the culture, which was filtered through four layers of cheesecloth to remove mycelial debris. The conidial suspension was washed three times in sterile distilled water by decanting the supernatant after centrifugation of the conidial suspension at $10,000 \times g$ for $1 \mathrm{~min}$, and adjusted to $1.0 \times 10^{7}$ conidia per $\mathrm{ml}$ with a hemacytometer.

Four inoculation methods were used: postharvest or in planta and wound or nonwound inoculations. Capsicum annuum cv. Jejujaerae and Capsicum baccatum cv. PBC80 were used as susceptible and resistant plants, respectively (51). Fully grown green fruit (approximately 30 days after pollination) were used for the postharvest inoculation test. Pepper fruit were surface-sterilized in $1 \%$ sodium hypochlorite for $3 \mathrm{~min}$, washed in sterile distilled water three times, and placed in a plastic container ( 30 by 20 by $7 \mathrm{~cm}$ ) lined with four layers of paper towel moistened with sterile distilled water to produce a humid environment. The conidial suspension was dropped on four or five sites on each fruit $(10 \mu \mathrm{l}$ per site) with or without wounding the fruit by needle pricking. Control fruit were inoculated with $10 \mu \mathrm{l}$ of sterile distilled water with or without wounding. The container was then covered with a plastic lid and kept in darkness at $25^{\circ} \mathrm{C}$ in an incubator. For in planta inoculations, half-grown pepper fruit (approximately 20 days after pollination) of the same cultivars were inoculated with $10 \mu \mathrm{l}$ of the conidial suspension. The inoculated fruit was covered with a clean plastic bag in which sterile distilled water was sprayed to maintain humidity and allowed to continue to grow on the plant. Symptom development (lesion formation) on the pepper fruit was observed daily for up to 10 days after inoculation.

Light microscopy and transmission electron microscopy of infected pepper fruits-measuring cuticle thickness and examining structural changes. After inoculation with the spore suspension, the inoculated fruit tissues were excised, and half were hand-sectioned with a razor blade. The sections were observed under a light microscope (Axiophot, Zeiss, Germany) after staining with $0.1 \%$ toluidine blue $O$. The other halves of the same tissues were fixed with Karnovsky's fixative (2\% paraformaldehyde and $2 \%$ glutaraldehyde in $0.05 \mathrm{M}$ cacodylate buffer at $\mathrm{pH}$
7.2) (15), washed in the same buffer, and postfixed in $1 \% \mathrm{OsO}_{4}$ for $2 \mathrm{~h}$. The fixed fruit tissues were washed briefly in distilled water and stained en bloc in $0.5 \%$ uranyl acetate overnight. They were dehydrated in an ethanol series $(30,50,70,80,95$, and $100 \%$ ) and embedded in Spurr's epoxy resin (43). Sections of 1- to $2-\mu \mathrm{m}$ thickness (semithin sections) were cut with a glass knife on an ultramicrotome (RMC, Inc., Tucson, AZ) and mounted on glass slides. The semithin sections were stained using the Quickie staining method (12) and observed under a light microscope. To measure cuticle thickness, semithin sections of nonwounded postharvest inoculation sites and adjacent noninoculated sites were examined under the light microscope. Four sites each on three pepper fruits (12 replications per treatment) were examined for each treatment after $0,4,12,18,72$, and $168 \mathrm{~h}$ of incubation. The cuticle layers stained grayish green. The significance of cuticle thickenings was tested by analysis of variance for inoculation effects (treatments) and cuticle thickness of inoculated and uninoculated sites was compared by Fisher's least significant difference pairwise comparisons in the SAS system (SAS Institute, Cary, NC).

For transmission electron microscopy (TEM), embedded samples were thin-sectioned (thickness, 80 to $90 \mathrm{~nm}$ ) with a diamond knife on the ultramicrotome. The sections were stained with $2 \%$ uranyl acetate and lead citrate for 7 min each and examined under an electron microscope (JEM-1010; JEOL, Japan) at $80 \mathrm{kV}$. At least three samples were observed per treatment each time.

Terminal deoxynucleotidyl transferase-mediated dUTP nick end labeling to detect programmed cell death. Cleavage of genomic DNA during programmed cell death (PCD) can yield double-stranded, low-molecular-weight DNA fragments (mono- and oligonucleosomes) and single-strand breaks in high-molecularweight DNA (50). To detect nuclear DNA cleavage, hand-cut sections of pepper fruit tissues $(\approx 50 \mu \mathrm{m}$ thick) were subjected to the terminal deoxynucleotidyl transferase (TdT)-mediated dUTP nick end labeling (TUNEL) procedure using a fluorescein-dUTP-based in situ cell death detection kit (Roche Applied Science, Indianapolis, IN). The sections were treated for $20 \mathrm{~min}$ at 15 to $25^{\circ} \mathrm{C}$ with freshly prepared fixation solution (4\% paraformaldehyde in phosphate-buffered saline [PBS], $\mathrm{pH} 7.4$ ), washed for $30 \mathrm{~min}$ with PBS, and permeabilized with $0.1 \%$ Triton X-100 in $0.1 \%$ sodium citrate. After permeabilization, the sections were rinsed twice with PBS, and $50 \mu \mathrm{l}$ of TUNEL reaction mixture was dropped onto each section. Sections were incubated in a humidified chamber for $60 \mathrm{~min}$ at $37^{\circ} \mathrm{C}$ in the dark. After rinsing three times with PBS, the samples were promptly examined under a confocal laser scanning microscope (Radiance-2000, Bio-Rad, UK) with excitation at 450 to $500 \mathrm{~nm}$. Yellow to greenish fluorescence was seen at 515 to $565 \mathrm{~nm}$ (HQ 515 30 emission filter).

DNA extraction and agarose gel electrophoresis to detect PCD. Genomic DNA was isolated using a simplified method, as previously described (35). C. gloeosporioides-infected tissues were excised from pepper fruit with a razor blade and placed in 15-ml tubes. Infected tissues were harvested at 2, 3, 5, and 7 days after inoculation and immediately placed in liquid nitrogen. The frozen tissues were ground in liquid nitrogen with a mortar and pestle. One milliliter of lysis buffer was added to the ground tissue and mixed thoroughly in a $2-\mathrm{ml}$ tube; the tube was incubated at $50^{\circ} \mathrm{C}$. After $1 \mathrm{~h}, 100 \mathrm{ml}$ of $10 \% \mathrm{~N}$-lauroylsarcosine was added, and the lysis mixture was incubated at $55^{\circ} \mathrm{C}$ for $1 \mathrm{~h}$. The cell debris was pelleted by centrifugation at 5,000 rpm. The supernatant was transferred to a new 2-ml tube, and the proteins were extracted twice using $1 \mathrm{ml}$ of phenol/chloroform (1:1). Genomic DNA in the supernatant was precipitated by adding 0.6 volume of isopropanol followed by centrifugation at $10,000 \mathrm{rpm}$ for $10 \mathrm{~min}$. The DNA pellet was washed with $70 \%$ ethanol before dissolving it in $100 \mu \mathrm{l}$ of TE buffer. The samples were electrophoresed on a $1.2 \%(\mathrm{wt} / \mathrm{vol})$ agarose gel, stained with ethidium bromide $(0.5 \mu \mathrm{g} / \mathrm{ml})$ for $45 \mathrm{~min}$, and visualized under UV illumination. 


\section{RESULTS}

Symptom development. C. gloeosporioides isolate 47-3 caused severe symptoms, such as sunken necrotic lesions (Fig. 1A), on the fruit of the susceptible pepper Capsicum аппиит cv. Jejujaerae, regardless of whether wound or nonwound and postharvest or in planta inoculations were used. The fruit tissues were severely rotted, forming acervuli at the later stages. In contrast, in the resistant pepper Capsicum baccatum cv. PBC80, nonwound postharvest inoculation (Fig. 1B) and wound in planta inoculation produced small black or brown specks. In the resistant pepper, wound postharvest inoculation induced lesions that were typically smaller than those on the susceptible pepper, but large lesions sometimes formed at the later stages of infection, as in susceptible plants. However, no lesions formed on the resistant fruit with nonwound in planta inoculation. Therefore, further light microscopy (LM) and TEM studies were conducted using pepper fruits treated with nonwound postharvest and wound in planta inoculations.

Light microscopy of the inoculated tissues ( 7 days after inoculation) showed altered and intact cellular morphology in the susceptible and resistant responses, respectively (Fig. 1C and D). Figure $1 \mathrm{C}$ is the marginal area of the anthracnose lesion in the susceptible fruit, showing a developed acervulus in the cuticle. The cell walls were ruptured, and no cellular contents were viewed under LM. Conversely, in the resistant pepper, a few necrotic cells were located just beneath the inoculation site, and no cellular damage was observed (Fig. 1D). The collenchyma cells of the subepidermal pericarp contained numerous inclusions of variable size, which probably contained phenolic compounds. No acervuli were found in the resistant fruit, unlike that in the susceptible fruit.

LM of cuticle thickening. The cuticle thickness of pepper fruit was measured using LM of semithin sections of nonwound post-

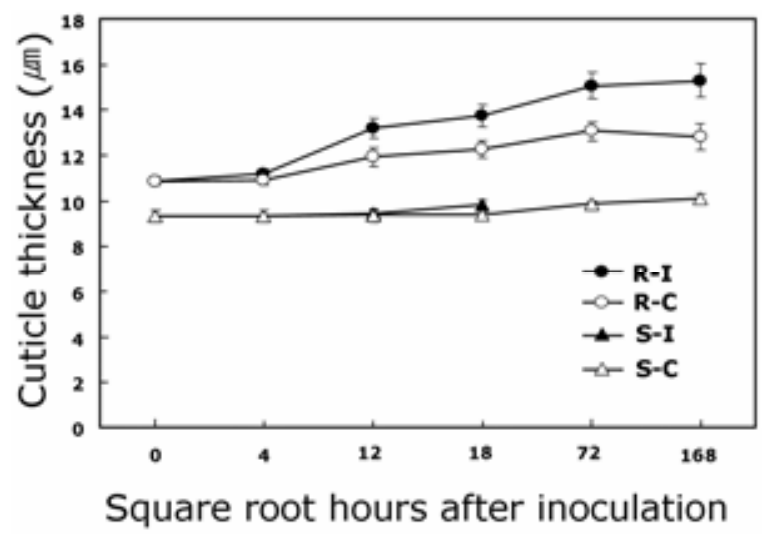

Fig. 2. Changes in cuticle thickness at the inoculation site (-I) and adjacent noninoculated site (-C) after inoculation of Colletotrichum gloeosporioides on Capsicum annuum cv. Jejujaerae (susceptible; S) and Capsicum baccatum cv. PBC80 (resistant; R). Cuticle thickness is shown as the mean (12 replications) with error bars denoting the standard deviation for each mean. Statistical analyses were performed to test the significance in inoculation effects on cuticle thickenings and differences in cuticle thickness between the susceptible and resistant pepper plants by the least significant difference pairwise comparisons.
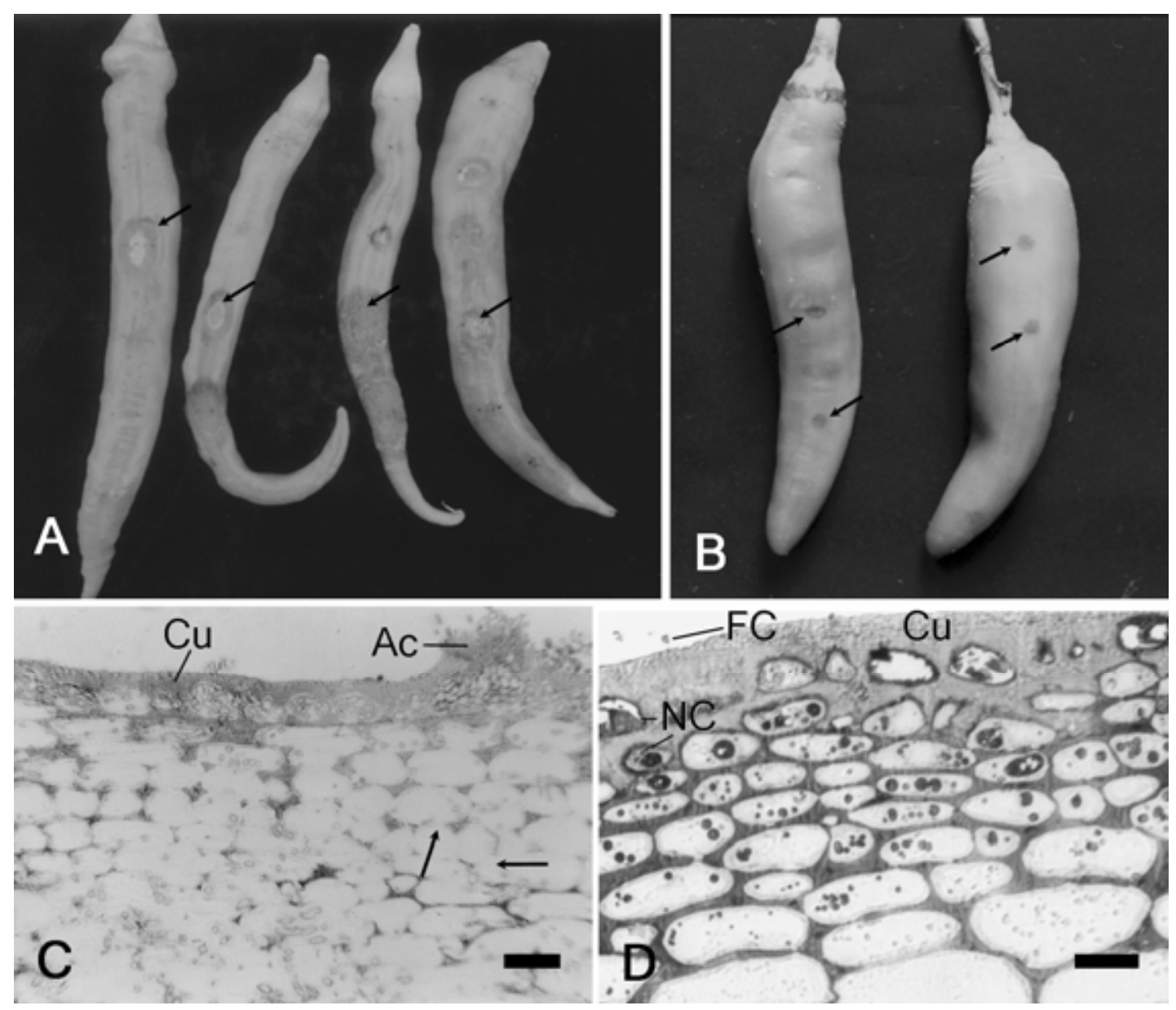

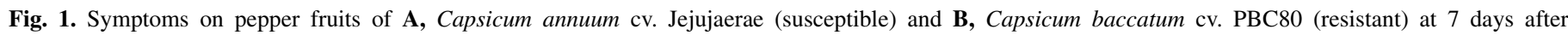

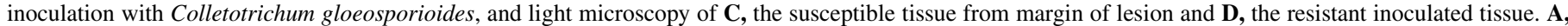

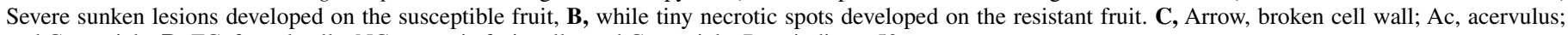
and $\mathrm{Cu}$, cuticle. D, FC, fungal cells; $\mathrm{NC}$, necrotic fruit cells; and $\mathrm{Cu}$, cuticle. Bars indicate $50 \mu \mathrm{m}$. 
harvest inoculation sites. The cuticle thickness of healthy mature green fruit differed greatly between the susceptible and resistant peppers. The cuticle of the inoculated sites thickened significantly with time after inoculation in the resistant fruit compared with that of noninoculated sites (Fig. 2). A significant difference in cuticle thickness was noted between inoculation and noninocula- tion sites beginning $12 \mathrm{~h}$ after inoculation. At the end of the study (168 $\mathrm{h}$ after inoculation), the average cuticle thickness of resistant pepper was $15.3 \mu \mathrm{m}$ at the inoculated sites versus $12.8 \mu \mathrm{m}$ at the noninoculated sites. In susceptible pepper fruit, there was no significant difference in cuticle thickness between inoculated and noninoculated sites. Cuticle thickness could not be measured later
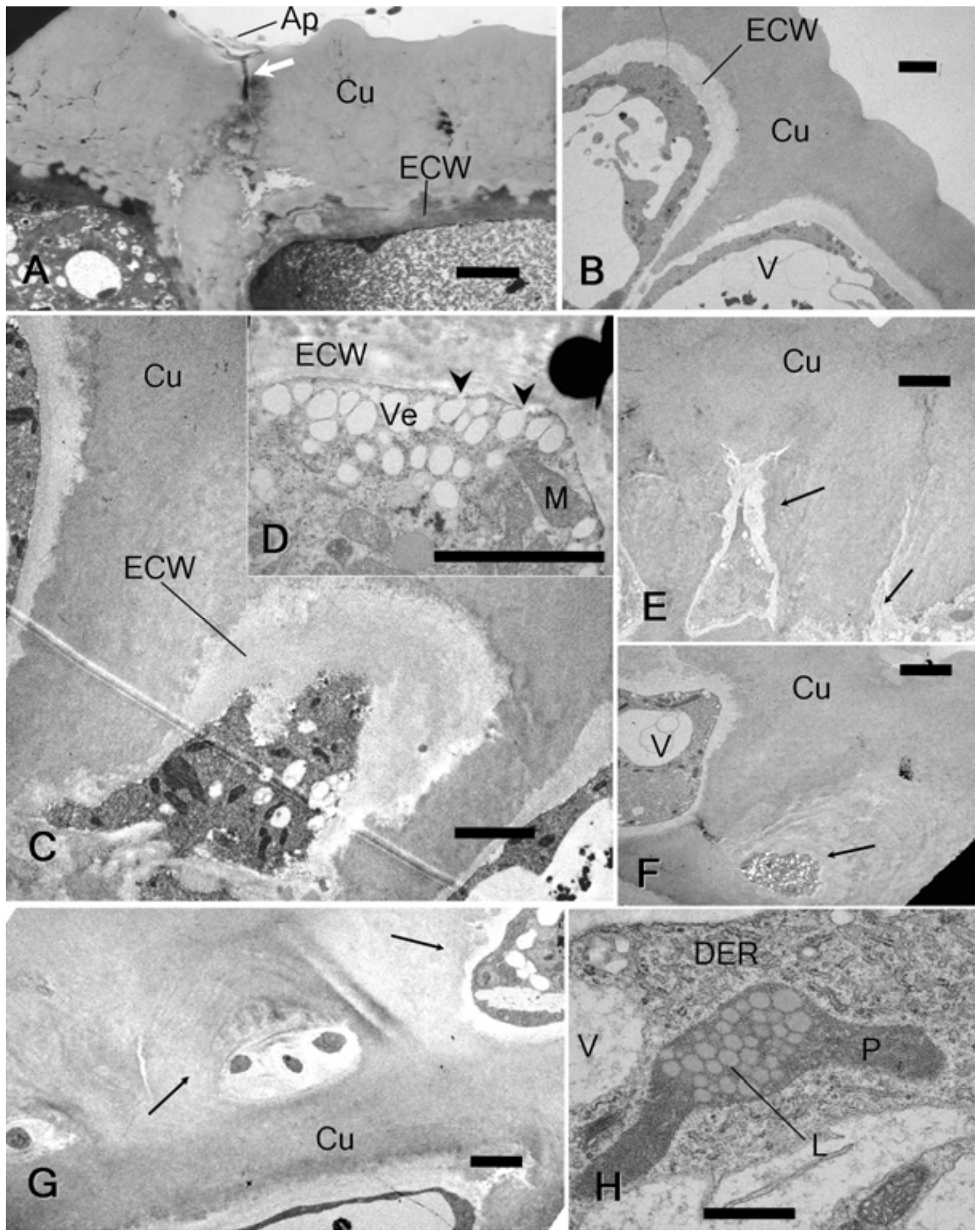

Fig. 3. Transmission electron micrographs of the cuticle and epidermis of the pericarp in A, Capsicum annuum cv. Jejujaerae (susceptible) and B to $\mathbf{H}$, Capsicum baccatum cv. PBC80 (resistant) after inoculation with Colletotrichum gloeosporioides. A, Infection site at $120 \mathrm{~h}$ after inoculation. Note the penetration site (arrow) in the cuticle $(\mathbf{C u})$. B, Noninoculated control is comparable to pericarp tissue at $72 \mathrm{~h}$ after inoculation. $\mathbf{C}$ to $\mathbf{H}$, Infection sites at $\mathbf{C}$ and $\mathbf{D}, 8 ; \mathbf{E}, 12 ; \mathbf{F}, 18 ;$ and $\mathbf{G}$ and $\mathbf{H}, 72 \mathrm{~h}$ after inoculation showing cuticle layer thickening (arrows) and related cytological features. $\mathbf{E}$ to $\mathbf{G}$, Cuticular materials were increased around epidermal cells, some of which were sometimes almost completely embedded in cuticle. D, Numerous vesicles (Ve) in the epidermal cytoplasm were produced adjacent to the outer cell wall beneath the cuticle layer, and for some, their contents were apparently incorporated in the cell wall (arrowhead). $\mathbf{H}$, Numerous lipid globules $(\mathrm{L})$ were formed in plastids $(\mathrm{P})$ with proliferated dilated endoplasmic reticulum (DER) in the cytosol. $\mathrm{Ap}=\mathrm{Appressorium} ; \mathrm{V}=$ vacuole; $\mathrm{Cu}=$ cuticle layer; $\mathrm{ECW}=$ epidermal cell wall; and $\mathrm{M}=$ mitochondria. Bars indicate $3 \mu \mathrm{m}$. 
than $18 \mathrm{~h}$ after inoculation in the susceptible peppers because the fruit tissue was severely rotten before $72 \mathrm{~h}$ after inoculation.

Electron microscopy of cuticle thickening. The pepper fruit tissues were also observed using electron microscopy. Appressorium formation and hyphal penetration through the cuticle were observed with TEM. At the inoculation site, the cuticle layer of the resistant fruit thickened with time, while no additional cuticle thickening was observed at inoculated sites of the susceptible pepper fruit (Fig. 3A) or at noninoculated sites of the resistant pepper fruit (Fig. 3B). Ultrastructural examination revealed that the cuticle thickening and potentially related cytological changes, which occurred at the inoculation sites of the resistant pepper fruit, involved the layering of cuticular materials on the epidermal and possibly subepidermal cell walls (Fig. 3C and E to G). Cuticular material was increased around epidermal cells, some of which were almost completely replaced by the cuticle at the later stages (Fig. 3E to G). Numerous vesicles in the epidermal cytoplasm were produced adjacent to the outer cell wall beneath the cuticle layer, some of whose contents appeared to be incorporated into the cell wall (Fig. 3D). Numerous lipid globules were formed in plastids with proliferated dilated endoplasmic reticulum (DER) in the cytosol (Fig. 3H).

Confocal laser scanning microscope in PCD. No TUNELpositive nuclei were visible in infected susceptible or healthy resistant postharvest fruits (Fig. 4A and B). In inoculated postharvest resistant fruit, TUNEL-positive nuclei were observed in epidermal and subepidermal cells beginning 3 days after inoculation (Fig. 4C) and were numerous by 7 days after inoculation (Fig. 4D). Close observation revealed that some nuclei contained dis- persed DNA, indicating nuclear fragmentation, and this became more prominent by 10 days after inoculation (data not shown). Wound in planta inoculation resulted in an earlier appearance of TUNEL-positive nuclei than nonwound postharvest inoculation. While no TUNEL-positive nuclei were observed in fruits with wounds alone (Fig. 4E), the TUNEL-positive nuclei were found at 1,2 , and 3 days after wound in planta inoculation (Fig. 4F to $\mathrm{H}$ ).

DNA laddering. DNA from the resistant pepper fruits with nonwound postharvest inoculation produced a ladder of DNA fragments at intervals of about $200 \mathrm{bp}$, and this became clearer with time after inoculation (Fig. 5). Low-molecular-weight DNA was detected in pepper fruit beginning 2 days after inoculation; however, no clear DNA fragmentation was visualized in agarose gels at this stage. Ladders of DNA fragments that differed by less than $200 \mathrm{bp}$ in size were detected near a 500-bp marker $(\lambda /$ HindIII) in pepper fruit beginning 3 days after inoculation, and the visibility of the DNA laddering increased slightly with time. In susceptible fruit, the small DNA was not laddered, but smeared, indicating destruction of all DNA (Fig. 5).

Electron microscopy of cellular structural changes. In susceptible pepper fruit, cellular damage was observed at $10 \mathrm{~h}$ after inoculation, i.e., before fungal invasion, and was characterized by cell wall degradation and cytoplasmic condensation (Fig. 6A). Later, inter- and intracellular fungal penetration and colonization occurred, accompanying destruction of the affected cells (Fig. 6B and $\mathrm{C}$ ). No intact cellular organelles (including the nucleus) were detected in the damaged cells.

In the resistant pepper, appressorium formation and fungal penetration occurred at the early stage (Fig. 6D), as in the suscep-

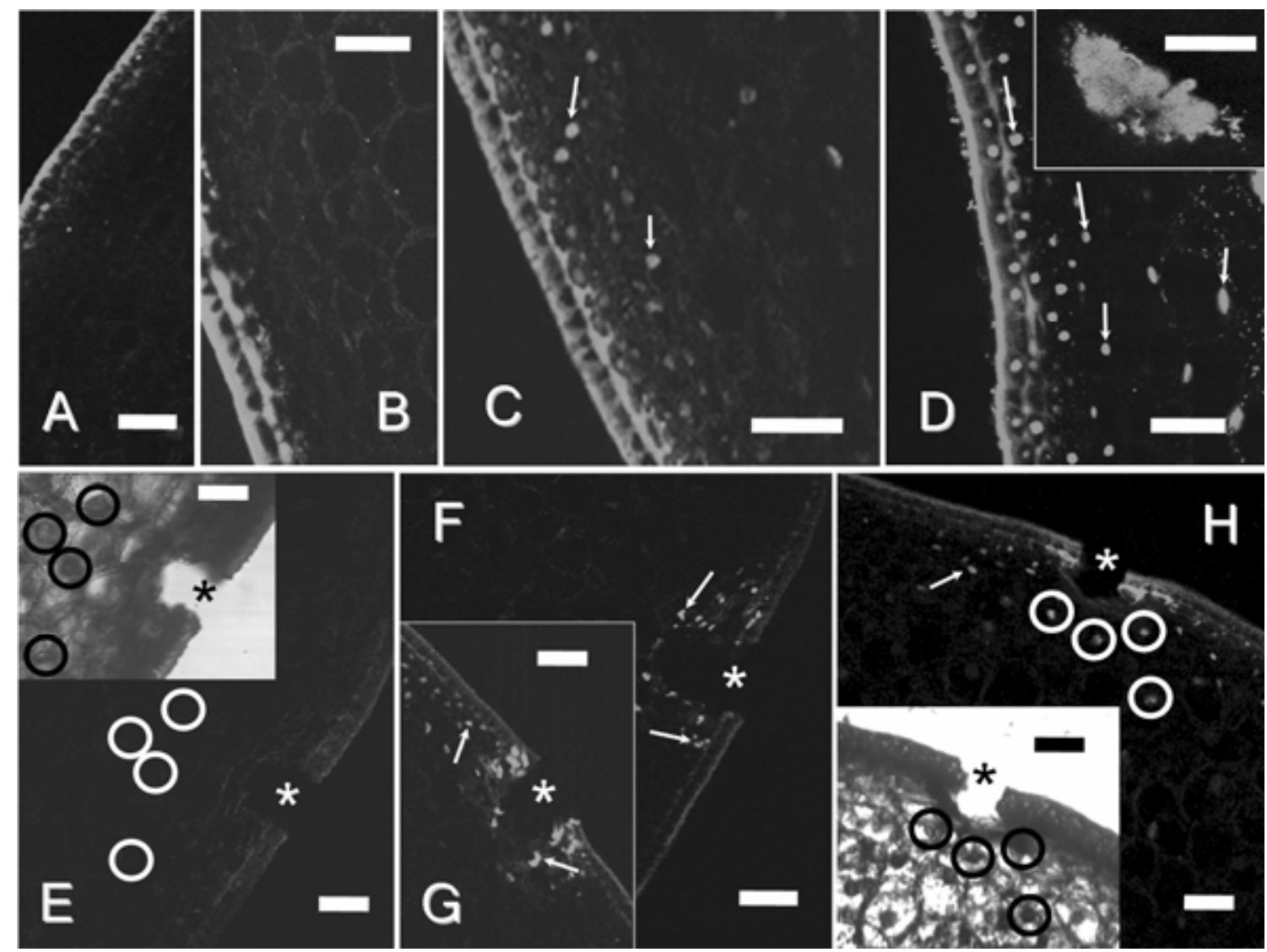

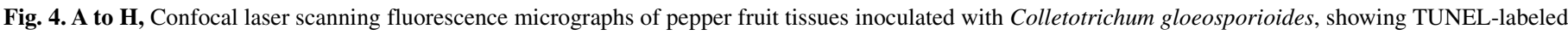

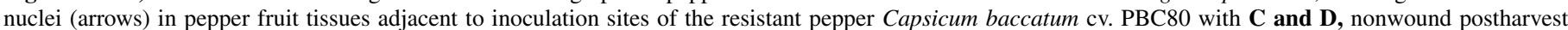

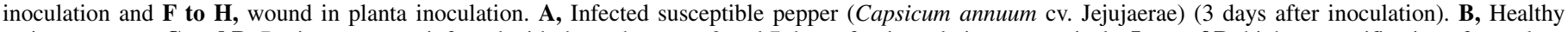

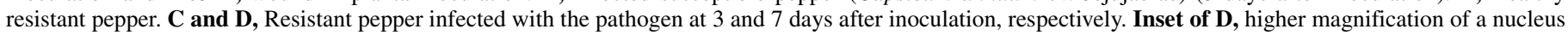

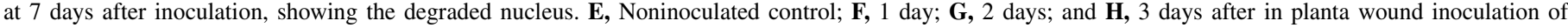

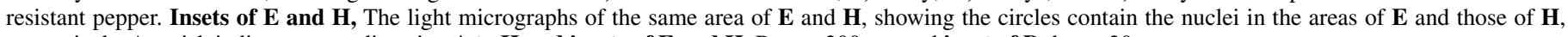
respectively. Asterisk indicates wounding site. A to $\mathbf{H}$ and insets of $\mathbf{E}$ and $\mathbf{H}, \mathbf{B}$ ars $=200 \mu \mathrm{m}$ and inset of $\mathbf{D}$, bar $=20 \mu \mathrm{m}$. 
tible peppers, followed by condensation of the cytoplasm with the formation of numerous small vacuoles (Fig. 6E). Unlike that in susceptible peppers, the endoplasmic reticulum (ER) was markedly dilated in the cytoplasm (data not shown). The separation of the plasma membrane from the cell wall was noted. Affected cells did not show much change in cellular appearance, but the nuclei were heterochromatic and less osmophilic (Fig. 6F and G) than were healthy nuclei (Fig. 6H). An increase in DER and the accumulation of electron-dense particles were also noted in the affected cells at the later stages of infection (data not shown).

Boundary layer formation with in planta wound inoculation at the later stages. With in planta inoculation, no visible symptoms developed on resistant fruit without wounding. Small necrotic spots developed in the resistant fruits with wound inoculation. Under LM of the wound inoculation sites, no definite cellular changes occurred by 1 day after inoculation (Fig. 7A). At 3 days after inoculation, necrosis was observed in parenchyma cells around the inoculation site (Fig. 7B). This necrotic area was autofluorescent under a fluorescence microscope (data not shown). Cell walls that crossed spherical parenchyma cells and led to cell division had frequently formed by 3 days after inoculation. Affected cells were enlarged at 5 days after inoculation (Fig. 7C), and cell division occurred in a series of cells and formed a layer by 7 days after inoculation (Fig. 7D). Boundary layers composed of several parallel cell layers were formed by 10 days after inoculation (Fig. 7E). Such cell division and boundary layer formation were not found in inoculated susceptible peppers (Fig. 7F). Similar cell enlargement and division were observed at 10 days after inoculation in the wound alone, but they appeared later and were far less conspicuous than in the wound-inoculated fruit (Fig. 7G).

\section{DISCUSSION}

Of the four inoculation methods, the nonwound postharvest and wound in planta inoculation methods were useful for examining the cellular modifications related to plant resistance responses. Typical symptoms sometimes developed with wound postharvest inoculation, whereas no symptoms were visible with nonwound in planta inoculation. Prusky et al. (39) postulated that differences in the postharvest physiological state of fruit affect their defense responses to fungal colonization. Active metabolism in postharvest fruits, such as the production of antifungal compounds, may slow with time and may not be sufficient to resist fungal growth if the first structural barrier, i.e., the cuticle layer, has been removed by wounding. This is supported by frequent observations that susceptible symptoms were more prevalent on older fruit after harvest

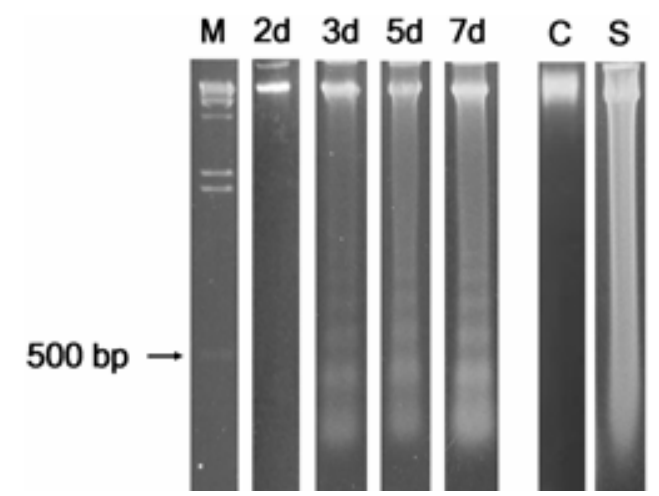

Fig. 5. Agarose gel electrophoresis of total genomic DNA extracted from inoculation sites of pepper fruit tissues in the resistant pepper (Capsicum baccatum) at 2 (2d), $3(3 \mathrm{~d}), 5(5 \mathrm{~d})$, and 7 (7d) days after inoculation with $\mathrm{Col}$ letotrichum gloeosporioides, showing DNA laddering. DNA laddering was noticed beginning 3 days after inoculation. $\mathrm{C}$ indicates healthy control. S indicates susceptible pepper at 7 days after inoculation, showing smeared DNA. $M$ is the size marker. than on fruit in planta (unpublished data). However, it is impossible to determine why no symptoms developed in resistant peppers with nonwound in planta inoculation. Perhaps the active resistance response of the in planta fruit was rapid enough to inhibit spore germination, appressorium formation, or cuticle penetration.

One of the problems in breeding pepper cultivars resistant to the fruit anthracnose is the inoculation method because disease severity due to the usual inoculation method for pepper fruit (detached wound inoculation) is variable depending on wounding depth (51). Our study also showed varied symptoms of the resistant pepper with detached wound inoculation. The nonwound postharvest and wound in planta inoculations resulted in rather uniform disease development, which seems to be more relevant for testing the disease responses of pepper fruit to the anthracnose disease.

In our study, resistant pepper fruit had thicker cuticles than did susceptible fruit. Relationships between a waxy cuticle and disease resistance have been found in many host-pathogen systems $(25,26,37,38)$. Stockwell and Hanchey (44) showed that the cuticle of bean hypocotyls was a barrier to infection by Rhizoctonia solani. The thick cuticle of the resistant pepper fruit is definitely a preexisting structural barrier to fungal penetration. In contrast, in the pepper-C. gloeosporioides system, Manandhar et al. (27) reported that the cuticle thickness of pepper fruit was not correlated with anthracnose lesion expansion, although it was negatively correlated with conidial production. This suggests that the preexisting cuticle of the resistant pepper fruit may be insufficient to prevent anthracnose disease development completely.

In nonwound postharvest inoculation, our study revealed two initial active mechanisms: cuticle thickening and PCD, a form of hypersensitive reaction. The cuticle is a polyester matrix of hydroxy and hydroxy epoxy fatty acids, $\mathrm{C}_{16}$ and $\mathrm{C}_{18}$ long (cutin), embedded and overlain with cuticular wax (22). Cuticle formation starts in the plastid with fatty acid synthesis and progresses with the modification of cutin monomers in the cytoplasm of epidermal cells $(20,33)$. The cutin monomers are transported to the outermost surface of the epidermal cell via the cell wall, where polymerization occurs with their incorporation into cutin primers (20). In the resistant pepper in our study, numerous lipid globules were formed in the plastids, which suggests that the fungal infection stimulates fatty acid synthesis. Increased DER and vesicles may reflect the increased synthesis and movement of fatty acids to the outer cell; the acyl chains produced in plastids move to the ER for further elongation (21), and vesicle trafficking and exocytosis is one method of fatty acid transport (22). During plantpathogen interactions, nonspecific lipid-transfer proteins (nsLTPs) might transport lipids (cutin monomers) and form an nsLTP-cutin monomer complex with an antifungal nature. This complex binds to a plasmalemma receptor and triggers plant defense responses by forming other nsLTPs and pathogenesis-related proteins (8). The nsLTPs also indicate the involvement of the synthesis and repair of cutin on the outer surface of the epidermal cell during pathogen-plant interactions. This suggests that cuticle thickening is a normal phenomenon in the defense responses against pathogen infection, especially for tissues with thick cuticles.

The occurrence of PCD and hypersensitive reactions in the resistant pepper upon pathogen infection was examined using the TUNEL method, electrophoresis of fragmented DNA, and electron microscopy. Oligonucleosomal fragments with 3 '-OH ends are indicative of endonucleolytic cleavage and are typically detected using in situ cytological methods, such as DNase I-mediated in situ translation, TUNEL, or enzyme-linked immunosorbent assay. Of these, the TUNEL method is useful for localizing modified nuclei. In our study, a positive TUNEL reaction occurred consistently around the inoculation sites in the resistant pepper, but not in the susceptible pepper. The reaction was de layed with nonwound postharvest inoculation compared with that 


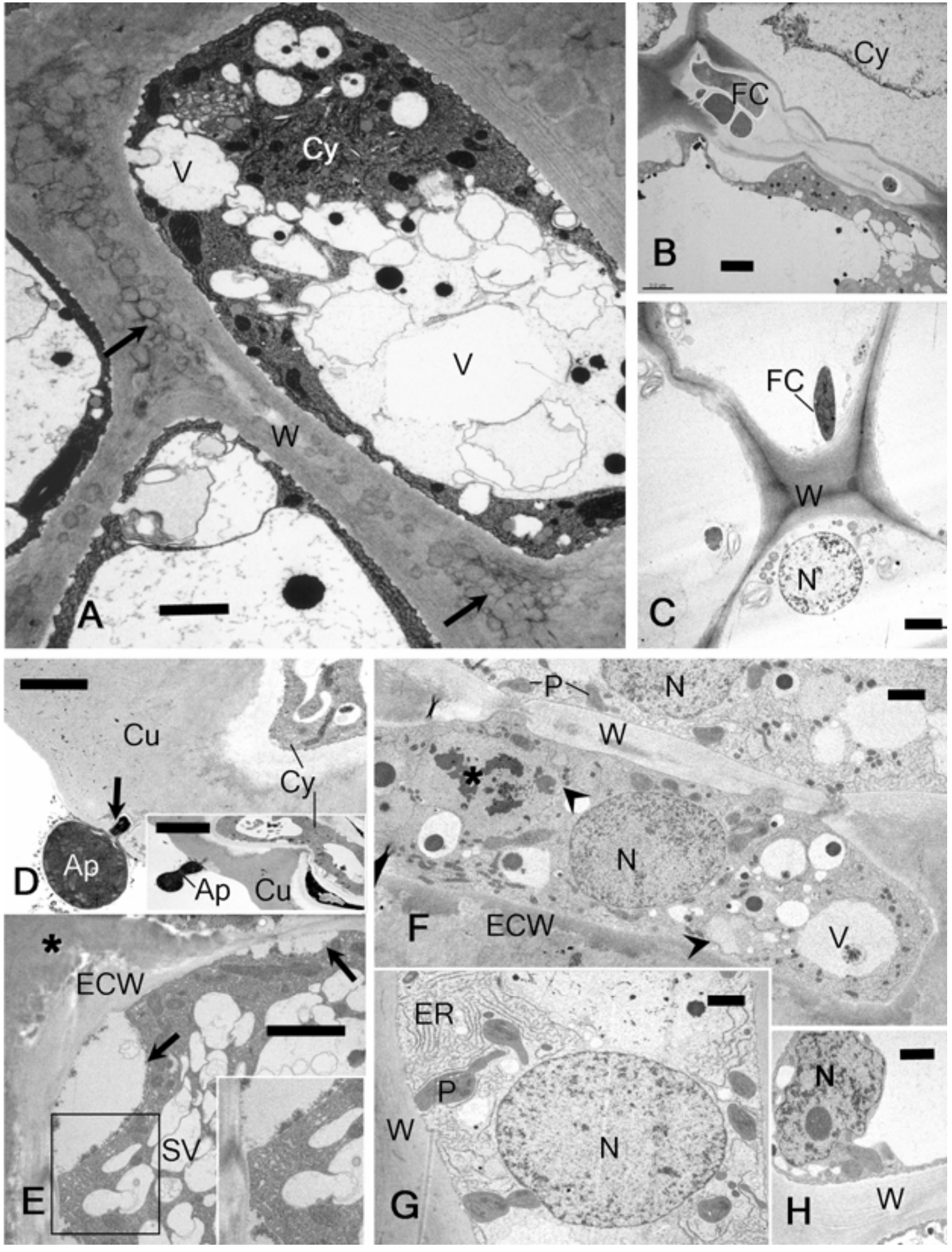

Fig. 6. Electron micrographs of A to C, Capsicum annuиm cv. Jejujaerae (susceptible) fruit and D to H, Capsicum baccatum cv. PBC 80 (resistant) fruit inoculated with Colletotrichum gloeosporioides. A, At $10 \mathrm{~h}$ after inoculation, showing degraded cell wall $(\mathrm{W})$ (arrow) and cytoplasm $(\mathrm{Cy})$ and fragmented vacuoles $(\mathrm{V})$. Bar $=$ $2 \mu \mathrm{m}$. B and C, Fungal cells were seen B, intercellularly and C, intracellularly at $120 \mathrm{~h}$ and at $168 \mathrm{~h}$ after inoculation, respectively. The cytoplasm is completely degraded or almost empty. Note the degraded nucleus $(\mathrm{N})$ in $\mathbf{C}$ with little nucleoplasm. Bars $=3 \mu \mathrm{m}(\mathbf{B})$ and $5 \mu \mathrm{m}(\mathbf{C})$. D, Penetration of the pathogen through the cuticle $(\mathrm{Cu})$ by forming infection hypha (arrow). The cytoplasm became condensed. Inset, Another area of fungal penetration. Bars $=5 \mu \mathrm{m}(\mathbf{D})$ and $15 \mu \mathrm{m}$ (inset). E, Separation of the plasma membrane (arrow) from the epidermal cell wall (ECW). Note numerous small vacuoles (SV) and newly added cuticle (asterisk). Inset of $\mathbf{E}$, Magnification of the rectangle in $\mathbf{E}$, showing proliferation of dilated endoplasmic reticulum. Bar $=3 \mu \mathrm{m}$. F, Epidermal cells with programmed cell death at 7 days after inoculation (the same site as Figure 4D), showing a less osmophilic nucleus (N). Note increased fibril-form euchromatin in the nucleus. Small vacuoles $(\mathrm{V})$ were increased and vacuole rupture was prominent (arrowhead), containing cytoplasmic or sometimes fragmented osmophilic inclusions (asterisk) $(\mathrm{bar}=2 \mu \mathrm{m}) . \mathrm{ECW}=$ epidermal cell wall, $\mathrm{P}=$ plastids, $\mathrm{V}=$ vacuole, and $\mathrm{W}=$ plant cell wall. $\mathrm{G}$, Nucleus $(\mathrm{N})$ in a cell with programmed cell death at 5 days after inoculation $(\mathrm{ER}=$ endoplasmic reticulum $)(\mathrm{bar}=1 \mu \mathrm{m}) . \mathbf{H}$, Nucleus $(\mathrm{N})$ in a noninoculated healthy cell $(\mathrm{bar}=2 \mu \mathrm{m})$. 
of wound in planta inoculation. This is probably due to the time taken for cuticle penetration in nonwound inoculation.

There would have been stronger evidence for PCD if the endonucleolytic cleavage did not involve general DNA breakdown, but rather endonuclease-mediated cleavage into internucleosomal fragments, a hallmark and characteristic of apoptotic cell death (50). One of the simplest hallmarks found in many situations in plants is the oligonucleosomal fragmentation of genomic DNA by an endogenous $\mathrm{Ca}^{2+} / \mathrm{Mg}^{2+}$-dependent endonuclease into discontinuous ladder fragments approximately 180 to $200 \mathrm{bp}$ apart, which are seen as a DNA ladder pattern on agarose electrophoresis $(10,29)$. This implies the occurrence of controlled cell death, because a DNA ladder is the product of chromatin digestion by nucleases without concurrent protease activity (i.e., no histone digestion) (40). We detected laddering in DNA from $C$. gloeosporioidesinoculated resistant pepper fruit. No DNA laddering was detected in noninoculated control resistant pepper fruits. DNA laddering was first detected at 3 days after inoculation, at the same time as the positive TUNEL reaction was first detected. This means that the DNA cleavage detected by the TUNEL method is the very same endonuclease-mediated oligonucleosomal fragmentation of genomic DNA that indicated PCD.

There were structural differences between the susceptible and resistant pepper fruit, especially at the late stages. Initially, the epidermal cytoplasm was condensed and small vacuoles were increased in both pepper fruits; however, cell destruction extended more to subepidermal cells in the susceptible pepper than in the resistant pepper. The cell walls were probably damaged by pathogen enzymes. However, no fungal structure was observed in the adjacent cell wall at the early stage, suggesting that infection occurred in a necrotrophic manner. The susceptible pepper fruit tissues were colonized inter- and intracellularly by the fungus at the later stages, leading to cellular degeneration. During the infection process in the susceptible pepper, no biotrophic infection
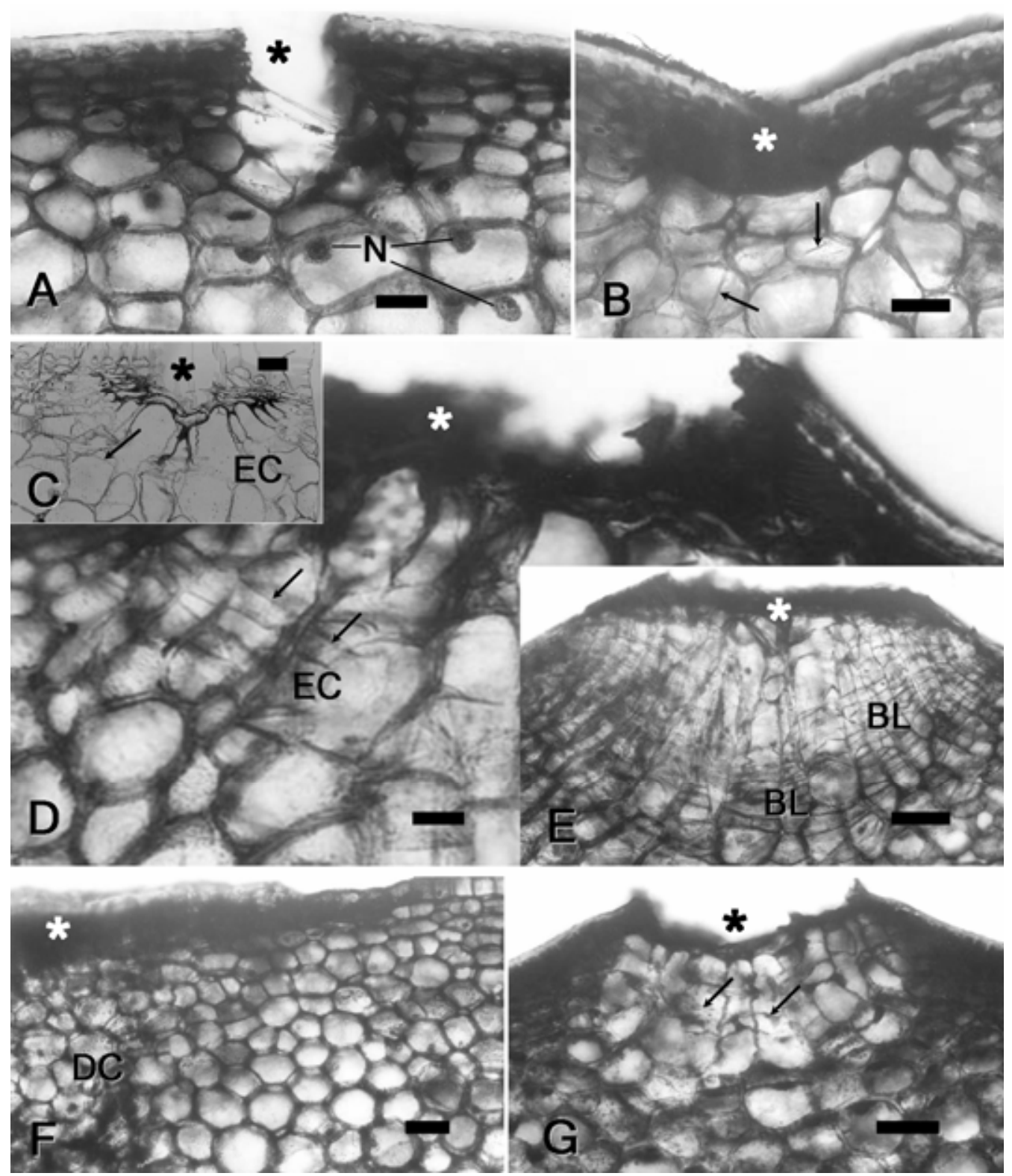

Fig. 7. Light micrographs of hand-cut sections of pepper fruit with wound in planta inoculation in Capsicum baccatum cv. PBC80 at $\mathbf{A}, 1 ; \mathbf{B}, 3 ; \mathbf{C}, 5 ; \mathbf{D}, 7 ;$ and $\mathbf{E}$, 10 days after inoculation with Colletotrichum gloeosporioides, and $\mathbf{G}$, at 10 days after wounding without fungal inoculation. F, Capsicum annuum inoculated with C. gloeosporioides (10 days after wound in planta inoculation). With a wound alone (G), only a few cell divisions occurred with no definite boundary layer formation, and in the susceptible pepper $(\mathbf{F})$, no boundary layer was formed. DC $=$ damaged cells. Bars $=100 \mu \mathrm{m}(\mathbf{A}$ to $\mathbf{D})$ and $200 \mu \mathrm{m}(\mathbf{E}$ to $\mathbf{G})$. Asterisks indicate wounding or inoculation sites. Note cell division (arrow) in enlarged cells (EC) and the extensive boundary layer (BL) formed by numerous parallel cell divisions. 
vesicles were found in infected epidermal cells, as seen in $C$. sublineolum-infected sorghum leaf (49). These structural features indicate that infection of pepper fruits by $C$. gloeosporioides was governed by necrotrophic fungal growth.

Few resistant fruit tissues were colonized by the fungus, although spore germination, appressorium formation, and direct penetration of the cuticle by infection hyphae occurred in cuticle and epidermal cells, along with the corresponding cellular modifications. The ultrastructural changes observed in resistant peppers included plasma membrane separation from the cell wall, vacuole rupture (accompanying cytoplasmic fragmentation and condensation), dilation of the rough ER, and nucleosomal changes. These cellular changes are similar to the changes seen in tomato cells exposed to the AAL toxins secreted by Alternaria alternata f. sp. lycopersici (47) and in cowpea cells infected with an incompatible strain of rust fungus, Uromyces vignae, or exposed to $\mathrm{KCN}$ (40). Such plant cell death resembles the changes characteristic of apoptosis in animals, suggesting that the cell death due to fungal infection is PCD and a hypersensitive response. The ER is profoundly dilated in the hypersensitive resistance reaction to the soybean-to-soybean cyst nematode (11). Vacuole rupture is an indication of PCD in the differentiation of the tracheary elements in zinnia and triggers rapid nuclear degradation (30). The area where PCD was detected by TUNEL contained fewer osmiophilic nuclei with less chromatin than in unaffected areas and was almost free of surrounding heterochromatin underneath the nuclear envelope. Fibrillar euchromatin was more prominent in the PCD nucleus than in the healthy one. We observed PCD and cuticle thickening in epidermal cells simultaneously. We suggest that there are genetic, biochemical, and structural relationships between PCD or hypersensitive responses and cuticle thickening, reflecting various defense mechanisms.

The lesions were always minimal on the resistant pepper with wound in planta inoculation, whereas the lesions were extensive on susceptible pepper with postharvest inoculation. Other resistance mechanisms may occur in the resistant pepper during the growth stages, without which the necrotrophic pathogen may overcome the initial PCD and hypersensitive reaction of the resistant pepper and continue its growth. In our study, boundary layer formation was observed around the wounded inoculation sites after the initial PCD responses, which may be related to another resistance mechanism, induced structural modification. The layer was formed by periclinal or parallel divisions of cells adjacent to wounded tissue, occurring before or concomitant with cell enlargement. Consequently, it separated the healthy tissue underneath from the infected or wound tissue above.

Kim and Kim (18) found similar structural changes in Peruvian apple cactus infected with $G$. cingulata or treated with an ethanol extract of the fungal culture. They suggested that the boundary layer is an abscission layer because the tissues outside the layer abscise. In the resistant pepper, no separation of infected fruit tissue from healthy tissue was observed in our study. It was structurally similar to wound periderm because it involved the division of parenchymatous cells and compact cell layers without weakening the boundary layer. Weakening of the abscission zone (boundary layer) before organ separation typically occurs in most abscission systems (48). Wound periderm is a histological defense structure that forms in response to wounding and invasion by parasites $(6,9,39,42)$ and can be induced by the wound itself $(7,9)$. Wounding itself could induce the processes needed for boundary layer formation in the resistant pepper; however, it may have been stimulated by the fungal inoculation. Unlike with wounding alone, necrosis was more extensive around the inoculation sites and autofluorescence was prominent in the necrotic region (unpublished data), which indicates the accumulation of phenolics $(19,24,28,46)$. Phenolics in the necrotic region may play an important role in inhibiting the initial fungal growth into parenchyma cells (41). Because there are no other outside factors in- volved in active boundary formation, the initial responses, such as PCD, the hypersensitive reaction, and necrosis, and the accumulation of autofluorescent materials may be responsible for its stimulation. More studies are needed to prove the relationships between the initial resistance responses and subsequent defense reactions.

Our study suggests that several mechanisms are involved in the defense of resistant pepper fruits against $C$. gloeosporioides infection and that these depend on host factors, such as postharvest or in planta and wound or nonwound. Prusky et al. (39) suggested that the resistance of fruits and vegetables to Colletotrichum spp. resulted from several gene interactions leading to dynamic incompatibility. The responses due to host resistance genes against pathogen gene products govern the growth of the pathogens. The cooperative expression of different pepper resistance genes to the anthracnose pathogen infection seems to be concomitant or consecutive and constitutes the entire defense system. In addition, resistance factors may be interrelated. If any one of the resistance components is missing, the plant may become less resistant or susceptible. Genetic and biochemical studies of these aspects should reveal more about multigene resistance mechanisms.

\section{ACKNOWLEDGMENTS}

This work was supported by Korea Science and Engineering Foundation thorough the Center for Plant Molecular Genetics and Breeding Research (CPMGBR) by a grant from BioGreen 21 Program, Rural Development Administration, Republic of Korea, and in part from Brain Korea 21 Project provided to K.-H. Kim. We thank Y. S. Kim and S.-H. Kwon for technical support in electron microscopy and confocal laser scanning microscopy, respectively.

\section{LITERATURE CITED}

1. Agrios, G. N. 1997. Plant Pathology. 4th ed. Academic Press, San Diego, CA.

2. Anderson, A. J. 1982. Preformed resistance mechanisms. Phytopathogenic Prokaryotes 2:119-137.

3. AVRDC. 1999. Off-season tomato, pepper and eggplant. Pages 20-30 in: AVRDC 1998 Progress Report. Asian Vegetable Research and Development Center, Taiwan.

4. Bailey, J. A., O'Connell, R. J., Spring, R. J., and Nash, C. 1992. Infection strategies of Colletotrichum species. Pages 88-120 in: Colletotrichum: Biology, Pathology, and Control. J. A. Bailey and M. J. Jeger, eds. CAB International, Wallingford, UK.

5. Berke, T., Black, L. L., and Liu, C.-A. 1999. Breeding for anthracnose and Phytophthora resistance in hot pepper (Capsicum annuum). J. Kor. Capsicum Res. Coop. 5:1-15.

6. Biggs, A. R., and Britton, K. O. 1988. Presymptom histopathology of peach trees inoculated with Botryosphaeria obtusa and $B$. dothidea. Phytopathology 78:1109-1118.

7. Biggs, A. R., and Stobbs, L. W. 1986. Fine structure of the suberized cell walls in the boundary zone and necrophylactic periderm in wounded peach bark. Can. J. Bot. 64:1606-1610.

8. Blein, J.-P., Coutos-Thévenot, P., Marion, D., and Ponchet, M. 2002. From elicitins to lipid-transfer proteins: A new insight in cell signalling involved in plant defence mechanisms. Trends Plant Sci. 7:293-296.

9. Burger, O. F. 1921. Variations in Colletotrichum gloeosporioides. J. Agric. Res. 20:723-736.

10. Eastman, A., Barry, M. A., Demarcq, C., Li, J., and Reynolds, J. E. 1994. Endonucleases associated with apoptosis. Pages 249-259 in: Apoptosis. E. Mihich and R. T. Schimke, eds. Plenum Press, New York.

11. Endo, B. Y. 1991. Ultrastructure of initial responses of susceptible and resistant soybean roots to infection by Heterodera glycines. Revue Nematol. 14:73-94.

12. Harris, W. M. 1978. Flattering and staining semithin epoxy sections of plant materials. Stain Technol. 53:298-300.

13. Jackson, A. O., and Taylor, C. B. 1996. Plant-microbe interactions: Life and death at the interface. Plant Cell 8:1651-1668.

14. Kalaitzis, P., Koehler, S. M., and Tucker, M. L. 1995. Cloning of a tomato polygalacturonase expressed in abscission. Plant Mol. Biol. 28:647-656.

15. Karnovsky, M. J. 1965. A formaldehyde-glutaraldehyde fixative of high osmolarity for use in electron microscopy. J. Cell Biol. 27:137A.

16. Keen, N. T. 1992. The molecular biology of disease resistance. Plant Mol. Biol. 19:109-122.

17. Keen, N. T., Ersek, T., Long, M., Bruegger, B., and Holliday, M. 1981. 
Inhibition of the hypersensitive reaction of soybean leaves to incompatible Pseudomonas spp. by blasticidin S, streptomycin or elevated temperature. Physiol. Plant Pathol. 18:325-357.

18. Kim, Y. H., and Kim, K.-H. 2002. Abscission layer formation as a resistant response of Peruvian apple cactus against Glomerella cingulata. Phytopathology 92:964-969.

19. Koga, H., Zeyen, R. J., Bushnell, W. R., and Ahlstrand, G. G. 1988. Hypersensitive cell death, autofluorescence, and silicon accumulation in barley leaf epidermal cells under attack by Erysiphe graminis f. sp. hordei. Physiol. Mol. Plant Pathol. 32:395-409.

20. Kolattukudy, P. E. 1996. Biosynthetic pathways of cutin and waxes and their sensitivity to environmental stresses. Pages 83-108 in: Plant Cuticle: An Integrated Functional Approach. G. Kerstiens, ed. BIOS Science Publishing, Oxford, UK.

21. Kroumova, A. B., and Wagner, G. J. 1999. Mechanisms for elongation in the biosynthesis of fatty acid components of epi-cuticular waxes. Phytochemistry 50:1341-1345.

22. Kunst, L., and Samuels, A. L. 2003. Biosynthesis and secretion of plant cuticular wax. Prog. Lipid Res. 42:51-80.

23. Latunde-Dada, A. O., O'Connell, R. J., Nash, C., Pring, R. J., Lucas, J. A., and Bailey, J. A. 1996. Infection process and identity of the hemibiotrophic anthracnose fungus (Colletotrichum destructivum O'Gara) from cowpea (Vigna unguiculata (L.) Walp.). Mycol. Res. 100:1133-1141.

24. Lummerzheim, M., de Oliveira, D., Castresana, C., Miguens, F. C., Louzada, E., Roby, D., Van Montagu, M., and Timmerman, B. 1993. Identification of compatible and incompatible interactions between Arabidopsis thaliana and Xanthomonas campestris pv. campestris and characterization of the hypersensitive response. Mol. Plant-Microbe Interact. 6:532-544.

25. Manandhar, J. B., Hartman, G. L., and Wang, T. C. 1995. Conidial germination and appressorial formation of Colletotrichum capsici and $C$. gloeosporioides isolates from pepper. Plant Dis. 79:361-366.

26. Manandhar, J. B., Hartman, G. L., and Wang, T. C. 1995. Semiselective medium for Colletotrichum gloeosporioides and occurrence of three Colletotrichum spp. on pepper plants. Plant Dis. 79:376-379.

27. Manandhar, J. B., Hartman, G. L., and Wang, T. C. 1995. Anthracnose development on pepper fruits inoculated with Colletotrichum gloeosporioides. Plant Dis. 79:380-383.

28. Mayama, S., and Shishiyama J. 1978. Localized accumulation of fluorescent and U.V.-absorbing compounds at penetration sites in barley leaves infected with Erysiphe graminis f. sp. hordei. Physiol. Plant Pathol. 13:347-354.

29. McConkey, D. J., and Orrenius, S. 1995. Calcium and cyclosporine in the regulation of apoptosis. Pages 95-105 in: Apoptosis in Immunology. G. Kroemer and C. Martinez, eds. Springer-Verlag, Berlin.

30. Obara, K., Kuriyama, H., and Fukuda, H. 2001. Direct evidence of active and rapid nuclear degradation triggered by vacuole rupture during programmed cell death in zinnia. Plant Physiol. 125:615-626.

31. O'Connell, R. J., Bailey, J. A., and Richmond, D. V. 1985. Cytology and physiology of infection of Phaseolus vulgaris by Colletotrichum lindemuthianum. Physiol. Plant Pathol. 27:75-98.

32. O'Connell, R. J., Perfect, S., Hughes, B., Carzaniga, R., Bailey, J. A., and Green, J. 2000. Dissecting the cell biology of Colletotrichum infection processes. Pages 57-77 in: Colletotrichum: Biology, Pathology, and Control. J. A. Bailey and M. J. Jeger, eds. CAB International, Wallingford, UK.
33. Ohlrogge, J., and Browse, J. 1995. Lipid biosynthesis. Plant Cell 7:957970 .

34. Osbourn, A. E. 1996. Preformed antimicrobial compounds and plant defense against fungal attack. Plant Cell 8:1821-1831.

35. Ou, S. S., Stafsud, O. M., and Basol, B. M. 1984. Current transport mechanisms of electrochemically deposited CdS/CdTe heterojunction. Solid-State Electron. 27:21-25.

36. Park, K. S., and Kim, C. H. 1992. Identification, distribution, and etiological characteristics of anthracnose fungi of red pepper in Korea. Kor. J. Plant Pathol. 8:61-69.

37. Podila, G. K., Rogers, L. M., and Kolattukudy, P. E. 1993. Chemical signals from avocado surface wax trigger germination and appressorium formation in Colletotrichum gloeosporioides. Plant Physiol. 103:267-272.

38. Podila, G. K., Rosen, E., San Francisco, M. J. D., and Kolattukudy, P. E. 1995. Targeted secretion of cutinase in Fusarium solani f. sp. pisi and Colletotrichum gloeosporioides. Phytopathology 85:238-242.

39. Prusky, D., Koblier, I., Ardi, R., Beno-Moalem, D., Yakoby, N., and Keen, N. T. 2000. Resistance mechanisms of subtropical fruits to Colletotrichum gloeosporioides. Pages 232-244 in: Colletotrichum: Biology, Pathology, and Control. J. A. Bailey and M. J. Jeger, eds. CAB International, Wallingford, UK.

40. Ryerson, D. E., and Heath, M. C. 1996. Cleavage of nuclear DNA into oligonucleosomal fragments during cell death induced by fungal infection or abiotic treatments. Plant Cell 8:393-402.

41. Silva, M. C., Nicole, M., Guerra-Guimaraes, L., Bresson, E., Rijo, L., Geiger, J. P., and Rodrigues, C. J., Jr. 1998. Cytological and biochemical aspects associated with the hypersensitive reaction in coffee plants infected with orange rust-Hemileia vastatrix. Abstract 1-2-35 in: Seventh International Congress of Plant Pathology, Vol. 2. Edinburgh, Scotland.

42. Smith, D. A. 1982. Toxicity of phytoalexins. Pages 218-252 in: Phytoalexins. J. A. Bailey and J. W. Mansfield, eds. Halsted Press, John Wiley \& Sons, New York.

43. Spurr, A. R. 1969. A low viscosity epoxy resin embedding medium for electron microscopy. J. Ultrastruct. Res. 26:31-43.

44. Stockwell, V., and Hanchey, P. 1985. Effect of cuticle treatments on infection of Phaseolus vulgaris in Rhizoctonia solani. J. Phytopathol. 114:6-12.

45. Strange, R. N. 1998. Plants under attack II. Sci. Prog. 81(Part 1):35-68.

46. Von Röpenack, E., Parr, A., and Schulze-Lefert, P. 1998. Structural analyses and dynamics of soluble and cell wall-bound phenolics in a broad spectrum resistance to the powdery mildew fungus in barley. J. Biol. Chem. 273:9013-9022.

47. Wang, H., Li, J., Bostock, R. M., and Gilchrist, D. G. 1996. Apoptosis: A functional paradigm for programmed cell death induced by a host-specific phytotoxin and invoked during development. Plant Cell 8:375-391.

48. Wharton, P. S., and Julian, A. M. 1996. A cytological study of compatible and incompatible interactions between Sorghum bicolor and Colletotrichum sublineolum. New Phytol. 134:25-34.

49. Wharton, P. S., Julian, A. M., and O'Connell, R. J. 2001. Ultrastructure of the infection of Sorghum bicolor by Colletotrichum sublineolum. Phytopathology 91:149-158.

50. Wyllie, A. H. 1980. Glucocorticoid-induced thymocyte apoptosis is associated with endogenous endonuclease activation. Nature 248:555-556.

51. Yoon, J. B. 2003. Identification of genetic resources, interspecific hybridization and inheritance analysis for breeding pepper (Capsicum anпиит) resistant to anthracnose. Ph.D. Thesis. Seoul National University, Korea. 